\title{
THÉODORE DE BÈZE, O LIBERUM VETO E OS "ARTIGOS DO REI HENRIQUE" DA POLÔNIA: AS ORIGENS DO ESPLENDOR CONSTITUCIONAL NO SÉCULO XVI E DA DECADÊNCIA POLÍTICA DA SERENÍSSIMA RES PUBLICA POLONIAE DIAGNOSTICADA POR ROUSSEAU NO SÉCULO XVIII
}

\author{
Silvio Gabriel Serrano Nunes ${ }^{1}$
}

\begin{abstract}
Resumo: Neste artigo, serão abordadas as repercussões da Filosofia Política de Théodore de Bèze no protagonismo da nobreza protestante da Polônia no século XVI, que culminou no documento constitucional "Artigos do Rei Henrique", cujo teor assinala, entre outras limitações ao poder real, a obrigação do rei de convocar o parlamento com regularidade, bem como de submeter os impostos extraordinários à assembleia parlamentar, declarar a guerra ou celebrar a paz somente depois da anuência da "Sejm" - o parlamento da Polônia dominado pela nobreza. Nesse período também são fortalecidas outras prerrogativas desse estamento, como o liberum veto. Apesar de não ter sido formalmente codificado o princípio do liberum veto, o caos experimentado pela Sereníssima República da Polônia, objeto de muitas das críticas de Rousseau à organização política polonesa, tem suas origens naquelas prerrogativas da nobreza garantidas no século XVI, como se demonstrará.

Palavras-Chave: Théodore de Bèze - Constitucionalismo - Artigos do Rei Henrique - Rousseau Polônia.
\end{abstract}

O presente texto tem por finalidade ${ }^{2}$ abordar as repercussões do pensamento político de Théodore de Bèze no protagonismo da nobreza protestante da Polônia no século XVI, que culminou no documento constitucional "Artigos do Rei Henrique", cujo teor assinala, entre outras limitações ao poder real, a obrigação do rei de convocar o parlamento com regularidade, submeter os impostos extraordinários à assembleia parlamentar da nobreza,

\footnotetext{
${ }^{1}$ Doutor em Filosofia pela Universidade de São Paulo. E-mail: serrano.nunes@gmail.com

2 Registramos que a motivação deste artigo parte da afirmação da Professora Dra. Maria das Graças de Souza, de que suas incursões em orientações sobre autores de Filosofia Política com matriz na tradição da Reforma Protestante se deve a Rousseau, nos termos do exemplar original de seu Memorial, com correções manuscritas da autora que guardo em um relicário em minha biblioteca.
} 
declarar a guerra ou celebrar a paz somente depois da anuência da "Sejm" - o parlamento da Polônia dominado pela nobreza -,sendo que nesse período também são fortalecidas outras prerrogativas dessa classe como o liberum veto.

Apesar de não ter sido formalmente codificado o princípio do liberum veto, o caos experimentado pela Sereníssima República da Polônia, objeto de muitas das críticas de Rousseau à organização política polonesa, tem suas origens naquelas prerrogativas da nobreza garantidas no século XVI, como se demonstrará.

No que tange à obra "Do Direito dos Magistrados", de Théodore de Bèze, publicada em 1574, a sexta questão, além de ser a mais importante, por analisar a tirania manifesta, também apresenta a peculiaridade de se afastar da exclusividade da autoridade bíblica e inserir exemplos seculares da história universal que chancelam a reação ativa em face da tirania.

O recurso à argumentação histórica é típico do gênero retórico judiciário, predominante no principal escrito político de Bèze, conforme explica Benoit Girardin:

O gênero judiciário, de longe, é o mais desenvolvido na herança retórica e determina uma ligação bem particular com a história: aquilo que está dentro do processo e em causa se encontra constituído de "fato". Em verdade, ele se ocupa inicialmente se isso se passou ou não (ansit), antes de perguntar o que se passou ou não (quid sit) e a qualificação judiciária requisitada. O que pertence à história é de tal modo colocado à distância, [em busca de] objetividade: fala-se sobre os fatos, raramente a partir deles.

O que se busca na história [...] são os exemplos. Os antigos praticaram e fizeram certas coisas, eis o que interessa, eis o que é útil aos contemporâneos. A segunda metade do século XVI italiano o manifesta claramente. O passado só se torna objetivo quando nele se buscam exemplos; ele deve edificar.

[...] O passado é sempre medido por uma instituição estabelecida: um corpo de leis, uma ética, o bom senso comum. $\mathrm{O}$ singular é sempre remetido à generalidade, o fato sempre medido por uma norma instituída antes dele. [...] O desejo da retórica se contempla se confirmar, se cumprir o que já era instituído, possível, desejável. ${ }^{3}$

O afastamento momentâneo da autoridade bíblica decorre da necessidade de uma fundamentação baseada num arcabouço teórico que Quentin Skinner denomina de constitucionalismo $^{4}$, o que requer amparo na historicidade. Uma vez que conceitualmente o constitucionalismo está associado à ideia de "governos moderados, limitados em seus poderes" 5 , é certo que, por extensão conceitual, apresenta os atributos de universalidade e bistoricidade, que geralmente são reconhecidos nos direitos fundamentais de primeira geração ${ }^{6}$, coincidentemente considerados marcos inaugurais do constitucionalismo do Ocidente ${ }^{7}$.

${ }_{3}^{3}$ GIRARDIN, Rhétorique et Théologique Calvin le Commentaire de l'Êpitre aux Romains. 1979, pp. 223-224.

${ }^{4}$ SKINNER, As Fundações do Pensamento Político Moderno. 2000, cap. 16.

${ }_{5}^{5}$ FERREIRA FILHO, Curso de Direito Constitucional. 1993, p. 7.

${ }^{6}$ BOBBIO, A Era dos Direitos. 1992, p. 70-71.

7 BONAVIDES, P. Curso de Direito Constitucional. 2007, p. 563. 
Bèze desenvolve a questão do recurso à história em sua fundamentação constitucionalista, de modo muito semelhante a uma de suas fontes da historiografia clássica, Tito Lívio, que na obra $A b$ Urbe Condita Libri, a mais citada pelo reformador genebrino dentre as obras da Antiguidade Clássica, assim expressa sobre a função moral da História para uma comunidade política:

[...] a meu ver, o que é preciso estudar com toda a atenção é a vida e os costumes de outrora, é a obra dos homens que na paz e na guerra ajudaram a construir e engrandecer o império. Em seguida, observar como o paulatino enfraquecimento da disciplina acarretou, por assim dizer, o relaxamento dos costumes e como sua decadência cada vez mais acentuada levou-os à queda brusca de nossos dias, quando a corrupção tanto quanto seus remédios nos parecem insuportáveis.

O que é sobremodo salutar e producente, no conhecimento da história, são os exemplos instrutivos de toda espécie que se descobrem à luz da obra [Ab Urbe Condita Libri]. Nela se encontram, para o teu benefício e o de teu país, modelos dignos de imitação assim como ações vergonhosas, cujas causas e consequências é preciso evitar ${ }^{8}$. Em outras palavras, Tito Lívio "atribui a seus personagens de eleição aquela soma de virtudes que convencionalmente associamos ao romano antigo. É sua convicção de que semelhantes virtudes não mais tinham lugar em meio à corrupção geral de sua época, propensa ao luxo, à moleza, à sensualidade". ?

De certa maneira, ao apontar tanto a degeneração que a tirania ocasiona no sistema político de sua época, na França dos $V$ alois afundada em conflitos religiosos, bem como os remédios contrários a tal tirania, Bèze tenta eleger modelos de liberdade e boa condução da política como havia feito na Antiguidade Clássica Tito Lívio, autor pertencente a uma geração de historiadores cujos paradigmas do passado estavam se perdendo enquanto as perspectivas de futuro revelavam-se muito imprecisas, conforme explica Jane D. Chaplin, ao referir-se aos exempla deste e de seus contemporâneos:

[...] ainda que os exempla naturalmente fizessem parte da tradição historiográfica na qual Lívio escreveu, seus contemporâneos, mais do que quaisquer outros historiadores, demonstram o paralelo mais próximo de tal interesse neles. Isso é especialmente verdadeiro para Augusto, que empregou os exemplos históricos extensivamente em sua reconstrução do mundo romano e fez particular uso da exemplificação na elegia em seu fórum. A conclusão sugere que os exempla tiveram um especial valor para uma geração cujo passado tinha entrado em colapso e cujo futuro era incerto. ${ }^{10}$

\footnotetext{
${ }^{8}$ LÍVIO, História de Roma (Ab Urbe Condita Libri). 1989, p. 18.

9 PEIXOTO, "Introdução". In: LÍVIO, Tito. Op. cit., p. 13.

${ }^{10}$ CHAPLIN, Livy's Exemplary History. 2000, p. 31
} 
Sobre as conexões entre história e pensamento político no século XVI, sem dúvida deve-se mencionar Maquiavel, que se destaca como grande devedor teórico de Tito Lívio e divulgador do valor do precedente histórico no seio da filosofia política.

Apesar de Théodore de Bèze, entre outros pensadores políticos huguenotes doséculo XVI, se contrapor direta ou indiretamente às ideias de Maquiavel, principalmente sobre a instituição do principado, é perfeitamente viável estabelecer um paralelo entre ambos no que concerne ao recurso à História. E no caso de Maquiavel, como explica Patrícia Fontoura Aranovich:

A razão por si só não tem clareza suficiente para sustentar uma posição e, apenas quando amparada pelos exemplos, assume a capacidade de ser um fundamento seguro para o conhecimento. Neste sentido, a imaginação, compreendida como a razão sem o apoio da história, não pode cumprir este papel. Maquiavel desqualifica aqui o que poderíamos chamar de pensamento abstrato da política ou, ainda, de ideal, assimilando-o à imaginação ou fantasia. O que guia esta perspectiva é a ideia de que, em Maquiavel, política e história não podem ser separadas, porque se o forem, serão insuficientes para a compreensão da realidade. Ou seja, a história é a única realidade e qualquer pensamento político deve ser nela fundada, sob pena de se tornar fantasmagórico. [...] Maquiavel afirma no capítulo 15 de O Príncipe [...] que não falará de repúblicas que jamais existiram, mas das que existiram e existem de fato e, já no primeiro capítulo do Príncipe, Maquiavel havia colocado a questão, senão nestes termos precisos, de um modo bastante claro, ao afirmar que seu objeto são os estados que existem e existiram, os estados reais. ${ }^{11}$

Se na obra O Príncipe, Maquiavel já sinaliza a importância da História para a argumentação de sua teoria política, na obra Discorsi enfatiza ainda mais o valor dos exempla para a teoria política, ao afirmar a função universal dos exemplos históricos para a boa ponderação antes da tomada de decisões políticas:

Quem considere as coisas presentes e as antigas verá facilmente que são sempre os mesmos os desejos e os humanos em todas as cidades e em todos os povos, e que eles sempre existiram. De tal modo que quem examinar com diligência as coisas passadas facilmente preverá as futuras, em qualquer república, prescrevendo os remédios que foram usados pelos antigos; ou, se não encontrar remédios já usados, pensará em novos, devido à semelhança dos acontecimentos. Mas, como essas considerações são negligenciadas ou não entendidas por quem lê, ou, se são entendidas, não são conhecidas por

11 ARANOVICH, História e Política em Maquiavel. 2007, pp. 27-29. 
quem governa, segue-se que sempre se veem os mesmos tumultos em todos os tempos. ${ }^{12}$

Após apresentar em tese os mecanismos institucionais para controlar e combater os tiranos e antes de inserir um amplo rol de exemplos históricos distribuídos num vasto espectro geográfico e cronológico, Bèze justifica categoricamente sua proposta semelhante a de Tito Lívio: "E de fato vejamos se em todos os tempos e em todas as nações mais conhecidas, se isso não foi assim praticado" $"$.

O recuo do uso da autoridade da história bíblica de afinidade teológica nesse capítulo constitui ponto crucial para abrir espaço à historiografia secular ou profana como autoridade na fundamentação do tratado, sobretudo a historiografia da tradição clássica. Mesmo quando citada a história de Israel nesse tópico de seu tratado, Bèze faz uma abordagem peculiarmente secular, conforme veremos.

Outro traço do recurso aos exemplos históricos é a sua disposição em ordem não cronológica, mas conforme sua importância, para compor uma teoria substancialmente convincente, que possibilite aos protestantes de seu tempo resistir em boa consciência contra a tirania dos Valois. Nesse sentido, Bèze justifica a exposição do paradigma da Roma Antiga logo de início e não o da Grécia Antiga, pois o primeiro conteria os fundamentos da monarquia francesa. Por essa mesma razão, finaliza circularmente a exemplificação, expondo a configuração de uma monarquia francesa condicionada, lastreada na própria história nacional francesa.

Referindo-se ao manejo não-cronológico dos exemplos históricos, Paul-Alexis Mellet assinala:

Em o Direito dos Magistrados, Bèze indica que a mesma 'regra de retidão' guia tanto os Cristãos como os Pagãos. No decorrer da longa lista de 13 exemplos ilustrando o poder dos magistrados, de resto ele aborda sucessivamente: os Romanos, os Atenienses, os Lacedemônios, a monarquia de Israel, antes de passar a exemplos mais recentes [como o da Polônia]. A distinção que fiz até aqui, entre os exemplos bíblicos e históricos, constitui assim um verdadeiro anacronismo. A lei de Deus inspirou, mesmo sem ter essa intenção, todos os homens. A partir disso, os exemplos podem ser tirados indistintamente da história bíblica, antiga, medieval ou mesmo moderna. ${ }^{14}$

Isso sugere, em última análise, que o recurso à história estaria atrelado à ideia de universalidade que Bèze pretende atribuir às suas teses de resistência.

12 MAQUIAVEL, Discursos sobre a primeira década de Tito Livio. 2007, p. 121.

13 BÈZE, Du Droit des Magistrats. 1970, p. 24.

${ }^{14}$ MELLET, "Du Passé au Présent: Les Sources du Droit des Magistrats sur leurs Sujets (1574) ". 2007, p. 541-542. 
Ao valer-se de exemplos de seus dias ou bem próximos a eles, referentes a outras nações, muitas das quais em processo de consolidação da Reforma Protestante, Bèze salienta o caráter próprio do Calvinismo, para o qual ele mesmo contribui, o internacionalismo desse ramo da fé reformada:

Os protestantes calvinistas tinham um credo e uma causa que ultrapassava as fronteiras e que se manifestava não apenas por meio de suas simpatias políticas, mas também pelos bolsos e bolsas. Os calvinistas ingleses interviram militarmente na Escócia, na primeira Guerra Religiosa na França e nos Países Baixos. Acolheram com satisfação e ajudaram a sustentar igrejas de "estrangeiros" franceses e holandeses em Londres e em outros lugares. Levantaram recursos para a defesa de Genebra contra o duque de Savoia na década de 1580 e para ajudar ao Palatinado, devastado pela Guerra dos Trinta Anos na década de 1620. Trata-se de uma história de soldados (voluntários ou mercenários) e de financistas. ${ }^{15}$

Como centro gravitacional da projeção internacional do Calvinismo, Patrick Collinson responsabiliza principalmente o próprio Bèze, fornecendo uma boa síntese do dinamismo intelectual e político deste autor, ao narrar a origem do Calvinismo da seguinte forma:

[O Calvinismo] Como sistema de ideias e práticas, entretanto, foi principalmente criado pela geração seguinte, especialmente Théodore de Bèze (1519-1605), conhecido como Beza, primeiro professor da Academia de Genebra, onde deu aulas durante quase quarenta anos. Beza se tornou sucessor de Calvino como o mais graduado da Companhia dos Pastores e conselheiro de igrejas e governos civis de status internacional. Foi Beza quem durante todos aqueles anos poupou o Calvinismo das lutas intestinas que esfacelaram o Luteranismo após a morte de Lutero. [...] A ordem da Igreja calvinista passou a ser considerada universalmente normativa, até mesmo nos Estados monárquicos, e uma carta de Beza sobre o tema dos bispos ajudou o lançamento do Presbiterianismo na Inglaterra e na Escócia (embora até mesmo Beza soubesse usar de brandura ao escrever a Elizabeth da Inglaterra). As políticas calvinistas se enrijeceram e Beza sancionou, como jamais fizera Calvino, o direito dos 'magistrados inferiores' de resistir a governantes tirânicos. ${ }^{16-17}$

Mesmo que Théodore de Bèze tenha revelado prudência quanto a ascender à liderança da Igreja Reformada em Genebra e se esforçado para que não lhe fossem confiados

15 COLLINSON, A Reforma. 2006, p. 121.

16 Nas mais diversas circunstâncias históricas e geográficas em que aparecesse o problema da tirania.

${ }_{17}$ COLLINSON, A Reforma. 2006, p. 122. 
tal encargo e honra de forma permanente, sempre teve consciência de sua missão como um protagonista no delicado arranjo político internacional de uma Europa dilacerada pelos conflitos religiosos, após o vazio deixado pela morte de Calvino. Algo aferido em sua correspondência a Zurique, logo depois do falecimento de seu antecessor: "Era um Francês ele e eu também sou Francês porque tal foi a vontade do Senhor. Mas Deus não deixou que nos deixássemos guiar [...] pela preocupação exclusiva de nossa pátria [...] devemos velar pelos homens que nós amamos, não apenas na qualidade de Franceses, mas como servidores da fé" 18 .

Dentre todos os exemplos citados por Bèze, a Polônia talvez seja o que melhor comprove sua argumentação quanto à neutralidade do constitucionalismo para salvaguardar o movimento reformador francês sem apelar para questões religiosas, capaz de captar inclusive a simpatia ou ao menos um espaço de negociação com o partido católico moderado (nos termos da visão geral de Skinner sobre a literatura calvinista continental do século $\mathrm{XVI})^{19}$.

Merece destaque a atuação diplomática de Bèze no delicado concerto europeu de então $\mathrm{O}^{20}$, em que a fé reformada apresentava-se como uma problemática política supranacional para as nações que lentamente se organizavam em termos políticos, sobretudo no caso da Polônia. Bèze teve papel relevante durante a dieta da eleição do novo rei na primeira metade da década de 1570, ocasião em que, de acordo com as predileções de Catarina de Médici, a coroa francesa tentava eleger como rei da Polônia Henrique, duque d'Anjou, irmão de Carlos IX, e para tanto a regente francesa necessitava negociar com ministros protestantes da Polônia $^{21}$, aconselhados por cartas e emissários de Genebra.

Para prover a defesa do candidato francês perante a dieta, fora designado o bispo católico de Valence, Jean de Monluc ${ }^{22}$. Bèze salienta que em um dos discursos do bispo

18 BÈZE, Documents - "La Réforme Française après la Mort de Calvin. Théodore de Bèze à H. Bullinger (Genève, 06 Août 1564)”. 1898, p. 600.

19 SKINNER, As Fundações do Pensamento Político Moderno. 2000, p. 576.

20 Kingdon aponta que os negócios poloneses nesse período ocupam demasiadamente a correspondência de Bèze, sobretudo com Bullinger, expoente da Igreja reformada em Zurich. (Cf. KINGDON, "Introdução”. 1970, p. XVIII).

${ }^{21}$ KINGDON, Op. cit., p. XVIII.

22 Jean Monluc, um homem da Igreja e do Estado, participou como diplomata na épocada regência de Maria de Guise na Escócia em 1548 e, posteriormente, em 06 de julho de 1560, conseguiu firmar o tratado com os lordes da Congregação da Escócia que disciplinava a retirada das tropas francesas e inglesas do solo escocês, em meio à conturbada revolução política e reforma religiosa lideradas por John Knox. Como hábil negociador, Jean Monluc atuou nas negociações que colocaram fim na primeira guerra religiosa e, na certa, por sua notável experiência nas tratativas com os protestantes da França e da Europa, "uma de suas grandes missões constituiu em ir à Polônia para preparar a eleição do duque d'Anjou. Ele formou uma equipe com seu filho natural, Jean Choisin, e outros. O bispo de Valence se colocou a caminho em 17 de agosto de 1572. Estava em Saint-Dizier quando tomou conhecimento da São Bartolomeu, o que lamentou. Acelerando sua chegada à Polônia, ali refutou vários escritos. Sua arenga em relação à dieta [citada por Bèze], iniciada em 3 de abril de 1573, teve grande sucesso. A eleição ocorreu entre 4 e 8 de março e coroou suas expectativas. Por contar com a confiança do novo rei, Henrique III, na França, passou a figurar na lista dos 79 membros do Conselho, de 17 de setembro de 1574, como também o Marechal [Monluc], seu irmão" (BOUCHER, "Monluc". 1998, p. 1111-1116). 
haveria o reconhecimento da validade de sua tese quanto ao comprometimento dos reis para com as leis, quando eleitos, tese defendida, todavia, pelo partido católico adversário da França.

Nas negociações prévias à eleição, com amplos poderes como procurador da coroa francesa, o bispo de Valence fez concessões a vários pontos das reivindicações protestantes $^{23}$ de tal forma que, depois de eleito e coroado, o duque d'Anjou teve que renunciar de forma tácita ao direito adquirido sobre o trono polonês, ao regressar à França em razão da morte de seu irmão Charles IX.

Diante dessas circunstâncias e graças às várias prerrogativas da nobreza, o peso da coroa polonesa era para Henrique mais "uma rocha sobre a cabeça" do que um símbolo de poder feito de metal nobre e pedras preciosas ${ }^{24}$.

Bèze, um dos articuladores das reivindicações dos protestantes ${ }^{25}$, descreve em seu tratado como os poloneses elegiam seus reis sob certas condições que uma vez descumpridas desobrigavam à obediência, o que não poderia ser mais posto em dúvida desde "a última eleição em que fizeram de Henrique, irmão do Rei da França, [tornar-se rei]" 26.

As condições a serem observadas mencionadas por Bèze são aquelas impostas pelos Artigos do Rei Henrique, um documento constitucional que já foi considerado um primeiro Bill of Rights, apto a instituir a "liberdade dourada" ${ }^{27}$ na Sereníssima Res Publica Poloniae ${ }^{28}$.

Assim como em Veneza, o controle da nobreza sobre aquele que ocupa a suprema magistratura executiva se mostraria como uma característica louvável de estabilização do regime político nos séculos XVI e XVII. Porém, essa reputação positiva seria gravemente abalada no século XVIII, como se constata nas incisivas críticas de Rousseau após seu diagnóstico a respeito da situação política polonesa e sua proposta de reformas para uma nova arquitetura constitucional.

Os Artigos do Rei Henrique, documento instituído após a Confederação de Varsóvia em 1573, consubstancia um "contrato constitucional fixo", vinculando todos os reis eleitos da República das Duas Nações desde então ${ }^{29}$.

Esse documento tinha por diretivas políticas principais: a Sejm (assembleia) tinha o poder de eleger o rei, que era proibido de buscar um sucessor em vida; o rei era obrigado a convocar a Sejm por seis semanas a cada dois anos; impostos extraordinários, decisões sobre a guerra e a paz dependiam da Sejm; era garantida a paz religiosa entre as denominações professadas na Polônia ${ }^{30}$.

23 KINGDON, "Introdução". 1970, p. XVIII-XIX.

${ }^{24}$ JOUANNA, et. al. Histoire et dictionnaire des guerres de religion, 1559-1598. 1998, p. 606.

${ }^{25}$ Genebra credencia e instrui o nobre huguenote Rémon, barão de Thyr, após requisição das igrejas reformadas da Polônia, para as negociações diretas e pessoais na eleição polonesa, porém o mesmo chega tarde demais para exercer qualquer influência (KINGDON, Op. cit, p. XVIII-XIX).

26 BÈZE, Op. cit., p. 33.

${ }^{27}$ JEDRUCH, Constitutions, Elections and Legislators of Poland. 1998, p. 84.

28 A Polônia também era chamada de "República das Duas Nações", devido à junção da Lituânia a essa comunidade política.

${ }^{29}$ ROHAC, "It Is by Unrule That Poland Stands" Institutions and Political Thought in the PolishLithuanian Republic. 2008, p. 218.

${ }^{30}$ ROHAC, Op.cit., p. 218. 
Segundo Dalibor Rohác, os Artigos do Rei Henrique representaram a codificação de privilégios e liberdades da nobreza já existentes. Ao parlamento polonês de então foram assegurados "poderes reais para formar controles eficientes para contrabalancear as ambições do monarca" $"$.

Já o liberum veto em nenhum momento específico da história polonesa foi propriamente codificado, de acordo com Dalibur Rohác, porém no século XVI tornou-se um verdadeiro princípio na dinâmica política da Polônia, tendo sido utilizado pela primeira vez de forma drásticano século XVII ${ }^{32}$, anulando uma sessão inteira da Sejm, em 1652.

Além dos Artigos do Rei Henrique, o parlamento sempre podia apresentar ao novo rei eleito um programa político específico chamado de Pacta Conventa, com cláusulas com as quais o rei deveria concordar ${ }^{33}$.

O caráter vinculativo de ambos os documentos e suas cláusulas era reafirmado pelo juramento dos reis da Polônia a cada eleição:

Ao aderir a todas as condições, artigos e pontos nestes [Artigos do Rei Henrique e Pacta Conventa] expressos, eu protegerei e guardarei a paz e a tranquilidade entre as religiões dissidentes. Não permitirei de forma alguma romper com estes ou aboli-los por qualquer jurisdição minha ou por qualquer autoridade de meus oficiais ou dos cargos do reino por questões religiosas. Eu mesmo não quebrarei ou abolirei [os artigos convencionados] [...] sem demora ou prorrogações e sem qualquer consideração privada, eu administrarei a justiça para todos os habitantes do Reino em concordância com as leis públicas que foram estabelecidas em todos os domínios. Se eu violar o meu juramento de qualquer forma, os habitantes do Reino e de todos os domínios de cada povo [que compõe o reino] não devem mais prestar a mim obediência. De fato, se eu violar [os artigos acordados], eu os libero de toda lealdade e obediência devida ao Rei. Eu não buscarei nenhuma absolvição nem a aceitarei se ela me for oferecida voluntariamente. Que Deus me ajude. ${ }^{34}$

Como argumento de autoridade para sua tese, cita o próprio mediador do partido oposto, o bispo católico Jean Monluc, que em "seu discurso pomposo impresso" 35 diz que

${ }^{31}$ ROHAC, Op.cit., p. 218.

32 ROHAC, Op. cit., p. 213-215.

33 ROHAC, Op. cit., p. 218-219.

34 Juramento dos Reis da Polônia, apud ROHAC, Op. cit., p. 219.

${ }^{35}$ Kingdon especula que a impressão do discurso Oratio ad ordines Poloniae in electione novi Regis citada por Bèze provavelmente teria ocorrido em 1573 na Cracóvia, havendo também ao menos "uma outra edição e traduções francesas, também impressas em 1573, mas na França, provavelmente depois da redação de Du Droit dês Magistrats" (KINGDON, "Nota 2." 1970, p. 34). Tivemos a oportunidade de analisar no setor de obras raras da Biblioteca Nacional da França uma edição francesa de 1573 com duas arengas de Jean Monluc proferidas por ocasião do processo eletivo do rei da Polônia, uma de 10 de abril de 1573 e outra de 25 de abril de 1573, esta última meramente para fazer elogios ao duque d'Anjou. Na primeira encontram-se elementos importantes para a teoria de Bèze, pois exaltava que na Gália natal do rei francês eleito para o trono polonês, os parlamentos (cortes de justiça) limitavam 
os poloneses "tem assim bem regulado e limitado o poder de seus Reis"36, ou seja, com a declaração do procurador da coroa francesa, fica reconhecida de forma inequívoca a validade universal das teses constitucionais de Bèze, limitadoras dos governantes, já que foram passíveis de reconhecimento por um membro do partido adversário ao deste autor.

Uma crítica contumaz a esses mecanismos de controle do poder, sobretudo pela nobreza, que são tão celebrados por Bèze, é elaborada por outro pensador clássico da Filosofia Política também associado a Genebra e suas virtudes republicanas. Trata-se de JeanJacques Rousseau, que aproximadamente dois séculos após a publicação do tratado de Bèze escreveu um ensaio com o sugestivo título de Consideracõoes sobre o Governo da Polônia e sua Reforma Projetada.

Ao fazer um diagnóstico da evolução histórica das práticas políticas dos poloneses, Rousseau parte da percepção de que na Polônia havia três classes: "os nobres, que são tudo; os burgueses, que não são nada; e os camponeses que são menos do que nada" "37. Apesar de reconhecer a eleição como meio de manter a liberdade, nota que no caso polonês cada reino se vale desse mecanismo para abalar o Estado como um todo ${ }^{38}$ e esclarece que o grande problema da Polônia seria o excessivo mecanismo de controle sobre o Poder Executivo, sobretudo por parte da nobreza, de modo a obstruir com tantos freios a regular possibilidade de se governar, elegendo como o pior deles o liberum veto ${ }^{39}$, instrumento pelo qual exigia-se a unanimidade do corpo representativo polonês para as decisões políticas.

Rousseau não considera o liberum veto um mal em si, mas o abuso do seu uso e a confusão gerada entre as funções legislativa e administrativa, que são causas de anarquia política, conforme explica:

os reis e, portanto, as prerrogativas da nobreza polonesa também eram familiares aos franceses. $\mathrm{Na}$ arenga de 10 de abril de 1573, Jean Monluc esclarece a verdadeira natureza da missão diplomática que presidia. Sua legação diplomática tinha o objetivo de dissipar fraudes e enganos sobre a candidatura do duque d'Anjou. Monluc explica à nobreza da Polônia que "A Gália sempre foi muito estimada e apreciada pelas nações estrangeiras por bem saber administrar a Justiça e dar o direito a cada um", de tal modo que "instituiu os parlamentos que parecem ter sido divinamente concedidos a nossos ancestrais, a fim de que [...] ao mais baixo e mais pequeno do povo mas principalmente aos nobres e gentil-homens fosse lícito agir e procurar por seus direitos na Justiça, mesmo [que a demanda fosse] contra o Rei". Jean Monluc consigna de forma cabal o respeito às prerrogativas da nobreza polonesa, pois esses direitos são reconhecidos, em um linguajar de nossos dias, como "direitos adquiridos", que não serão modificados pelo novo rei: "Quanto aos vossos privilégios, franquias, liberdades e imunidades, quanto aos vossos estados, ofícios e benefícios que se devem dar àqueles do país somente, não é preciso que nos coloquemos em pena [lamentação], pois tais coisas são vossas e não nossas. E quanto a nós, nós as manteremos sempre salvas e íntegras, sem que jamais as aspiremos". (MONLUC, "Harangue faicte et prononcée de la part du Roy très-chrestien, le 10. jour du mois d'avril 1573." Par... Jean de Montluc,... conseiller de Sa Majesté en son privé Conseil, \& son ambassadeur par devers... les archevesques, évesques, palatins, castellans, magistrats, officiers, \& généralement tout l'ordre \& estat de la noblesse du... royaume de Poulonne, grand duché de Lithuanie, Russie, Prusse... en l'assemblée tenue à Warsavie, pour l'élection du nouveau roy, après le décez du sérénissime Sigismund Auguste. 1573, p. 5, 11-12, 33).

36 BËZE, Op. cit., p. 34.

${ }^{37}$ ROUSSEAU, Considerações sobre o Governo da Polônia e sua Reforma Projetada. 1982, p. 42.

${ }^{38}$ ROUSSEAU, Op. cit., p. 99.

39 ROUSSEAU, Op. cit., p. 48-49. 
O liberum veto não é um direito vicioso em si mesmo, mas, assim que ultrapassa seu limite, torna-se o mais perigoso dos abusos. Ele era a garantia da liberdade pública; não é mais do que instrumento da opressão [...].

O liberum veto seria menos desarrazoado se incidisse unicamente sobre os pontos fundamentais da constituição; mas que tenha lugar geralmente em todas as deliberações das dietas é o que não se pode admitir de forma alguma. É um vício na constituição polonesa que a legislação e a administração não sejam suficientemente distinguidas; e que a dieta, exercendo o poder legislativo, a ele misture partes da administração, faça indiferentemente atos de soberania e de governo, frequentemente até mesmo atos mistos pelos quais seus membros são magistrados e legisladores ao mesmo tempo.

As mudanças propostas tendem a melhor distinguir os dois poderes e por isso mesmo marcar melhor os limites do liberum veto. Pois não creio que tenha alguma vez passado pelo espírito de alguém estendê-lo às matérias de pura administração, o que seria aniquilar a autoridade civil e todo o governo. ${ }^{40}$

Gustave Pétitain, em seu escrito Notícia Preliminar, uma concisa história da Polônia anexa à obra de Rousseau em análise desde as primeiras edições ${ }^{41}$, explica a forma abusiva pela qual a nobreza polonesa há séculos se valia de suas prerrogativas de representação nas Dietas:

Os nobres, apenas gozando assim dos direitos de cidade, reuniram-se periodicamente nas dietinas, ou 'dietas' de palatinado, para nelas eleger os 'núncios' encarregados de representá-la na dieta geral. Esta se reunia a cada dois anos e era composta do senado e dos representantes da nobreza; ela partilhava com o rei o poder legislativo.

A este germe sempre subsistente de confusão e de desordem acrescentavamse: 1) a dependência absoluta de cada núncio, resultando das instruções que lhe haviam sido dadas na dietina e da qual ele não podia se afastar; 2) o direito do liberum veto, que tornava a deliberação de toda e qualquer dieta infrutuosa pela oposição de um só membro, direito cujo uso não podia ser situado para além de 1650, mas de que os nobres poloneses se tinham desde então mostrado tão ciosos que ele se convertera em lei máxima do Estado. ${ }^{42}$

Em termos conclusivos, pode-se afirmar que a virtuosa forma aristocrática de governo da Polônia, que já fora chamada de "a liberdade dourada", celebrada por Bèze no século XVI, graças aos seus eficazes mecanismos de controle do poder real, principalmente na oportunidade das eleições do rei pela nobreza, foi posta em xeque por autores posteriores como J. J. Rousseau e Pétitain, ao explicitarem a degeneração numa oligarquia, que criava obstáculos insuperáveis para os instrumentos decisórios do Estado, ao impor a unanimidade

40 ROUSSEAU, Op. cit., p. 65.

41 FORTES, “Nota 1". 1982. p. 17.

42 PÉTITAIN, “Notícia Preliminar.” In: ROUSSEAU, Op. cit., p. 18. 
na deliberação dos corpos legislativos, gerando um quadro anárquico do regime político polonês.

\section{THÉODORE DE BÈZE, THE LIBERUM VETO AND THE "KING HENRY'S ARTICLES “OF POLAND: THE ORIGINS OF BOTH CONSTITUTIONAL SPLENDOR IN THE 16TH CENTURY AND POLITICAL DECADENCE OF THE MOST SERENE RES PUBLICA POLONIAE DIAGNOSED BY ROSSEAU IN THE 18TH CENTURY}

Abstract: This article will approach the repercussion of the Political Philosophyof Théodore de Bèze, related to the protagonism of the Polish Protestant nobility in century XVI, which culminated in the constitutional document "Articles of the King Henry". Among other restrictions to the royal power, the document appoints that: the king must call the parliament regularly as well as submit extraordinary taxes to the parliamentary assembly; the king only can declare war or celebrate peace with the consent of the "Sejm" - the Polish parliament, headed by the nobility. In this period, other prerogatives of this class are strengthened, like the liberum veto. Although the principle of the liberum veto was not formally codified, the chaos experienced by the The Most Serene Republic of Poland - object of many of Rousseau's criticism regarding the Polish political organization - has its origins in those prerogatives from the Sixteenth Century, as will be shown.

Keywords: Théodore de Bèze - Constitutionalism - Articles of the King Henry - Rousseau - Poland.

\section{REFERÊNCIAS BIBLIOGRÁFICAS}

ARANOVICH, Patrícia Fontoura. História e Politica em Maquiavel. São Paulo: Discurso Editorial, 2007.

BÈZE, Théodore de. "Documents - La Réforme Française après la Mort de Calvin. Théodore de Bèze à H. Bullinger (Genève, 06 Août 1564)". Bulletin de la Societé de l'Histoire du Protestantisme Français. Paris: n. 47, p. 594-603, 1898.

Du Droit des Magistrats. Genève: Droz, 1970.

BOBBIO, Norberto. A Era dos Direitos. Rio de Janeiro: Campus, 1992.

BONAVIDES, Paulo. Curso de Direito Constitucional. São Paulo: Malheiros, 2007.

BOUCHER, Jacqueline. "Monluc". In: JOUANNA, Arlette; BOUCHER, Jacqueline; BILOGHI, Dominique; LE THIEC, Guy. Histoire et dictionnaire des guerres de religion, 15591598. Paris: Robert Lafont, p. 1111-1116, 1998.

CHAPLIN, Jane D. Livy's Exemplary History. Oxford: Oxford University Press, 2000.

COLLINSON, Patrick. A Reforma. Rio de Janeiro: Objetiva, 2006.

FERREIRA FILHO, Manoel Gonçalves. Curso de Direito Constitucional. São Paulo: Saraiva, 1993. 
GIRARDIN, Benoit. Rhétorique et Théologique Calvin le Commentaire de l'Êpitre aux Romains. Paris: Éditions Beauchesne: 1979.

JEDRUCH, Jacek. Constitutions, Elections and Legislators of Poland. New York: Hippocrene Books, 1998.

JOUANNA, Arlette; BOUCHER, Jacqueline; BILOGHI, Dominique; LE THIEC, Guy. In: JOUANNA, Arlette; BOUCHER, Jacqueline; BILOGHI, Dominique; LE THIEC, Guy. Histoire et dictionnaire des guerres de religion, 1559-1598. Paris: Robert Lafont, p. 606, 1998.

LÍVIO, Tito. História de Roma (Ab Urbe Condita Libri). São Paulo: Paumape, 1989.

MAQUIAVEL. Discursos sobre a primeira década de Tito Livio. São Paulo: Martins Fontes, 2007.

MELLET, Paulo-Alexis. Du Passé au Présent: Les Sources du Droit des Magistrats sur leurs Sujets (1574). Théodore de Bèze (1519-1605): Actes du Colloque de Genève (septembre 2005), Travaux d'Humanisme et Renaissance, CDXXIV. Genève: Droz, 2007.

MONLUC, Jean. Harangue faicte et prononcée de la part du Roy très-chrestien, le 10. jour du mois d'avril 1573. Par... Jean de Montluc,... conseiller de Sa Majesté en son privé Conseil, \& son ambassadeur par devers... les archevesques, évesques, palatins, castellans, magistrats, officiers, \& généralement tout l'ordre \& estat de la noblesse du... royaume de Poulonne, grand duché de Lithuanie, Russie, Prusse... en l'assemblée tenue à Warsavie, pour l'élection du nouveau roy, après le décez du sérénissime Sigismund Auguste. Paris: Jean Richerlibraire, 1573.

PEIXOTO, Paulo Matos. "Introdução”. In: LÍVIO, Tito. História de Roma (Ab Urbe Condita Libri). São Paulo: Paumape, 1989.

ROHAC, Dalibor. "It Is by Unrule That Poland Stands" Instutions and Political Thought in the Polish-Lithuanian Republic. The Independent Review. Oakland: The Independent Institute, v. 13, n. 2, p. 209-224, 2008.

ROUSSEAU, J. J. Consideraşões sobre o Governo da Polônia e sua Reforma Projetada. São Paulo: Brasiliense, 1982.

FORTES, Luiz Roberto Salinas. "Nota 1”. In: ROUSSEAU, J. J. Considerações sobre o Governo da Polônia e sua Reforma Projetada. São Paulo: Brasiliense, 1982, p. 17.

SKINNER, Quentin. As Fundações do Pensamento Político Moderno. São Paulo: Companhia das Letras, 2000. 